"This is the Author's Accepted Manuscript version, uploaded in accordance with the publisher's selfarchiving policy. Please note: this is the author's version of a work that was accepted for publication in International Journal of Pharmaceutics. This journal has an embargo period of 12 months which begins from the publication date of the issue the article appears in. Changes resulting from the publishing process, such as editing, structural formatting, and other quality control mechanisms may not be reflected in this document. The definitive version is available at: http://dx.doi.org/10.1016/j.ijpharm.2015.10.047"

\title{
Modified local diatomite as potential functional drug carrier - a model study for diclofenac Sodium
}

Jelena Janićijevićc ${ }^{*}$, Danina Krajišnik ${ }^{\mathrm{a}}$, Bojan Čalija ${ }^{\mathrm{a}}$, Bojana Nedić Vasiljević ${ }^{\mathrm{b}}$, Vladimir Dobričićc, Aleksandra Dakovićd, Milan D. Antonijeviće ${ }^{\text {, Jela Milića }}$

${ }^{\text {a }}$ Department of Pharmaceutical Technology and Cosmetology, University of Belgrade-Faculty of Pharmacy, Vojvode Stepe No. 450, 11221 Belgrade, Serbia

b Faculty of Physical Chemistry, University of Belgrade, Studentski Trg No. 12-16, 11000 Belgrade, Serbia

${ }^{c}$ Department of Pharmaceutical Chemistry, University of Belgrade-Faculty of Pharmacy, Vojvode Stepe No. 450, 11221 Belgrade, Serbia

${ }^{\mathrm{d}}$ Institute for the Technology of Nuclear and Other Mineral Raw Materials, Bulevar Franš d'Eperea No. 86, 11000 Belgrade, Serbia

e Faculty of Engineering \& Science, University of Greenwich, Medway Campus, ME4 4TB, Chatham Maritime, Kent, UK

${ }^{*}$ Corresponding author. Tel.: +381 11 3951359; fax: +381 113972840

E-mail address: zoran.jan@ikom.rs 


\begin{abstract}
Diatomite makes a promising candidate for a drug carrier because of its high porosity, large surface area, modifiable surface chemistry and biocompatibility. Herein, refined diatomite from Kolubara coal basin, which complied with the pharmacopoeial requirements for heavy metals content and microbiological quality, was used as a starting material. Inorganic modification of the starting material was performed through a simple, one-step procedure. Significant increase in adsorbent loading with diclofenac sodium (DS) was achieved after the modification process $(\sim 373 \mathrm{mg} / \mathrm{g})$ which enabled the preparation of comprimates containing therapeutic dose of the adsorbed drug. Adsorption of DS onto modified diatomite resulted in the alteration of the drug's XRD pattern and FTIR spectrum. In vitro drug release studies in phosphate buffer $\mathrm{pH} 7.5$ demonstrated prolonged DS release over $8 \mathrm{~h}$ from comprimates containing DS adsorbed on modified diatomite (up to $37 \%$ after $8 \mathrm{~h}$ ) and those containing physical mixture of the same composition (up to $45 \%$ after $8 \mathrm{~h}$ ). The results of in vivo toxicity testing on mice pointed on potential safety of both unmodified (starting) and modified diatomite. All these findings favour the application of diatomite as a potential functional drug carrier.
\end{abstract}

Keywords: diatoms, porous silica, inorganic modification, adsorption, drug delivery, prolonged drug release. 


\section{Introduction}

Natural hierarchical structures have some unique features distinguishing them from the synthetic ones: they are produced by biologically controlled self-assembly at ambient temperature and atmospheric pressure through ecologically balanced processes, most often they are multifunctional and many of them have self-healing capacity and display properties that change in response to a changing environment (Meyers et al., 2008). Generally, natural hierarchical structures can be divided into three categories: hierarchical 1D fibers, 2D layers and 3D pores and some examples of natural hierarchical porous structures include glass sponge, human bone, kelp, coral, wood and diatoms. Owning to the presence of macro/meso structured porous system, the applications of these materials are emerging in various fields such as catalysis, separation processes, optics, energy, drug delivery and life sciences (Su et al., 2012).

Frustules, amorphous silica cell walls of diatoms, provide remarkable example of three dimensional organization in hierarchical porous structures where pores are organized in functional arrangement at different levels exhibiting macro-, meso- and microporosity. At the end of diatoms' life-cycle, frustules settle and accumulate on the ocean and freshwater floors creating a siliceous sedimentary rock - diatomite. Unique physicochemical properties of diatomite (low density, high porosity, large surface area, high absorptive capacity, low thermal conductivity and chemical inertness) enable its commercial use as filter aid, cement additive, filler and absorbent (U.S. Geological Survey, 2014). Furthermore, hierarchical porous structure of frustules inspired research on potential diatomite application in the fields of photonics, microfluidics, chemo- and biosensing, drug delivery and nanofabrication (Losic et al., 2009).

Interest in diatomite as potential drug carrier is increasing. Zhang et al. (2013) prepared diatoms' silica microparticles (DSM) loaded with mesalamine or prednisone by an immersion method and demonstrated subsequent prolonged drug release under simulated gastrointestinal conditions. Additionally, it was pointed that DSM can be considered non-cytotoxic biomaterial since cell 
viability assay on colon cancer cells (Caco-2, HT-29 and HCT-116) showed almost no toxicity at concentrations up to $1000 \mu \mathrm{g} / \mathrm{ml}$. Another study (Bariana et al., 2013) showed that surface modification of diatomite by covalent attachment of selected organosilanes and phosphonic acids may be an efficient method for tuning drug loading and drug release characteristics of diatomite. Incipient wetness method was applied for DSM loading with indomethacin or gentamicin sulfate and differences in drug loading capacities (14-24\%) and release periods (13-26 days), depending on functional groups present on the surface of modified diatomite, were observed. The abovementioned findings demonstrated the potential of diatomite, either unmodified or modified, to serve as a prolonged-release carrier for either acidic or basic drugs, as well as for drugs with different water solubility.

In our previous study (Janićijević et al., 2014) food grade diatomite was modified with the precipitation product of partially neutralized aluminum sulfate solution at three levels. A significant increase in adsorbent loading with model drug diclofenac sodium (DS) was achieved with samples at all three modification levels during adsorption batch experiments. Adsorbent loadings of the samples containing high and medium amount of the modifying agent were similar (about $266 \mathrm{mg} / \mathrm{g}$ and $262 \mathrm{mg} / \mathrm{g}$ respectively) but higher compared to the sample having low amount of the modifying agent (whose adsorbent loading was about $214 \mathrm{mg} / \mathrm{g}$ ). Modified diatomite sample showing high adsorbent loading at the lower level of modification (i.e. the sample prepared at the medium modification level) was chosen as a carrier for in vitro drug release studies. Prolonged drug release was observed not only from comprimates containing the adsorbed drug (18\% drug released after $8 \mathrm{~h}$ ), but also from the corresponding physical mixture of the drug and modified diatomite (45\% drug released after $8 \mathrm{~h})$.

The aim of this study was to investigate the possibility of applying chemically modified diatomite from a local source as a functional drug carrier. In order to further support potential pharmaceutical application of diatomite, heavy metals content and microbiological quality were examined for the 
starting diatomite according to appropriate pharmacopoeial prescriptions. Additionally, in vivo acute toxicity testing was performed for both unmodified and modified diatomite samples.

Domestic diatomite from Kolubara coal basin, after being purified by thermal treatment and sieving, was used as a starting material. Inorganic modification was performed by precipitation of partially neutralized aluminum sulfate in diatomite suspension at the level that was chosen as optimal in our previous work (Janićijević et al., 2014). The starting and modified diatomite were characterized by scanning electron microscopy (SEM), energy dispersive X-ray spectrometry (EDS), X-ray diffraction (XRD) analysis, Fourier transform infrared spectroscopy (FTIR), thermal analysis and evaluated for DS adsorption capacity in adsorption isotherm experiments. In vitro drug release studies were performed in phosphate buffer $\mathrm{pH} 7.5$ from comprimates containing: the drug adsorbed onto the starting diatomite (DD), the drug adsorbed onto the modified diatomite (MDD) and physical mixture of the drug with the modified diatomite (PMDD). Drug-release profiles for the abovementioned comprimates were fitted to various mathematical models in order to evaluate DS release mechanism and bring it in correlation with the proposed type of DS-carrier interactions.

\section{Materials and methods}

\subsection{Materials}

Diatomite from Kolubara coal basin was used after purification which included thermal treatment $\left(550{ }^{\circ} \mathrm{C}, 4 \mathrm{~h}\right.$ ) and sieving (particle size fraction lower than $125 \mu \mathrm{m}$ ). Aluminum sulfate hexadecahydrate $\left(\mathrm{Al}_{2}\left(\mathrm{SO}_{4}\right)_{3} \times 16 \mathrm{H}_{2} \mathrm{O}\right)$ was supplied from Centrohem d.o.o., Serbia, sodium hydroxide was purchased from Carlo Erba Reagenti, Italy, potassium phosphate monobasic from Sigma-Aldrich Chemie GmbH, Germany and absolute ethanol from Zorka-Pharma a.d., Serbia. Diclofenac sodium was supplied directly from pharmaceutical industry (Galenika a.d., Serbia). All 
reagents used were of analytical grade. Purified water ( $\mathrm{Ph}$. Eur. grade) was used through all experiments.

\subsection{Methods}

\subsubsection{Diatomite modification}

Specified amount of diatomite $(500 \mathrm{mg}$ ) was homogenously suspended in $50 \mathrm{ml}$ of aqueous aluminum sulfate solution $\left(0.02 \mathrm{~g} / \mathrm{ml} \mathrm{Al}_{2}\left(\mathrm{SO}_{4}\right)_{3} \times 16 \mathrm{H}_{2} \mathrm{O}\right)$ on a magnetic stirrer ( $\mathrm{RH}$ basic 2 , IKA ${ }^{\circledR}$ Werke GmbH, Germany). To the obtained suspension, which was still being magnetically stirred, $60 \mathrm{ml}$ of a base $(0.1 \mathrm{M} \mathrm{NaOH})$ was added in a thin jet from a rotating reservoir. Precipitate formed (inorganically modified diatomite-MD) was separated by filtration, dried in an oven $\left(60{ }^{\circ} \mathrm{C}, 4 \mathrm{~h}\right)$ and pulverized in a mortar with a pestle before further investigations.

\subsubsection{Characterization of the starting and modified diatomite before and after drug adsorption}

Limit test for heavy metals and biological tests for microbial contamination of products not required to comply with the test for sterility were conducted in accordance with the pharmacopoeial $(\mathrm{Ph}$. Eur. 6.0) prescriptions.

Scanning electron microscopy (SEM model JSM-6610LV, JEOL Ltd., Japan) in conjunction with energy dispersive X-ray spectrometry (EDS detector model X-Max Large Area Silicon Drift connected with INCA Energy 350 Microanalysis System) was applied to examine the morphology and chemical composition of the samples. Samples were mounted on an aluminum carrier with double-faced adhesive carbon tape and coated with thin layer of gold before analyzing. 
X-ray diffraction (XRD) patterns were recorded on a D8 Advance X-ray Diffractometer (Bruker, Germany) in theta-theta geometry in a reflection mode $(\mathrm{CuK} \alpha$ radiation at $40 \mathrm{kV}$ and $40 \mathrm{~mA}$; a primary Göbel mirror for parallel beam and removal of $\mathrm{CuK} \beta$ radiation; a primary $4^{\circ}$ Soller slit; a $0.2 \mathrm{~mm}$ exit slit; sample rotation at $15 \mathrm{rpm}$; a LynxEye silicon strip, position sensitive detector set with an opening of $3^{\circ}$, the Lynx Iris set at $6.5 \mathrm{~mm}$; a secondary $2.5^{\circ}$ Soller slit). The samples were scanned between 2 and $50^{\circ}(2 \theta)$, step size of $0.02^{\circ}$ and a counting time of 0.1 s per step; with 176 active channels in the detector this is equivalent to a total counting time of $17.6 \mathrm{~s}$ per step. Data were collected using DIFFRAC Plus Commander v.2.6.1 software (Bruker) and qualitative assessment of the data was performed with the aid of EVAv.16 (Bruker) software and the PDF-2 database (ICDD, 2008).

The Fourier transform infrared (FTIR) spectra were recorded using attenuated total reflection (ATR) technique on Nicolet iS50 spectrometer (Thermo Scientific, USA) with a diamond ATR smart accessory. Spectra were obtained by the co-addition of 256 scans over the range of $4000-400$ $\mathrm{cm}^{-1}$ with the spectrum resolution of $2 \mathrm{~cm}^{-1}$. A background scan was acquired before scanning the samples.

Thermal analysis was performed on a Netzsch STA 409 EP (Selb, Germany). Samples were heated from $20{ }^{\circ} \mathrm{C}$ to $1000{ }^{\circ} \mathrm{C}$ in an air atmosphere, at a heating rate of $10{ }^{\circ} \mathrm{C} \mathrm{min}-1$.

\subsubsection{Adsorption isotherm studies}

Prior to adsorption isotherm studies, adsorption kinetic experiments were performed and adsorption equilibrium time was determined to be $2 \mathrm{~h}$ for the starting diatomite and $6 \mathrm{~h}$ for the modified diatomite.

A stock DS solution (4 mg/ml) in water (containing $10 \% \mathrm{v} / \mathrm{v}$ absolute ethanol as a cosolvent) was prepared and adequately diluted to obtain working DS solutions (1 - $3.5 \mathrm{mg} / \mathrm{ml})$. Accurately weighted adsorbents ( $0.6 \mathrm{~g}$ of diatomite or modified diatomite) were transferred into Erlenmeyer 
flasks and $80 \mathrm{ml}$ of appropriate DS solution $(1-4 \mathrm{mg} / \mathrm{ml})$ was added. The flasks were closed and shaken on a laboratory shaker (KS 260 basic, IKA ${ }^{\circledR}$-Werke GmbH, Germany) at 200 rpm speed and room temperature. After reaching equilibrium, a small volume of each dispersion was withdrawn, centrifuged at $3000 \mathrm{rpm}$ for $2 \mathrm{~min}$ (MPW 56, MPW Med. Instruments, Poland) and DS concentration in the supernatant was determined spectrophotometrically $(275 \mathrm{~nm}$, Evolution 300 spectrophotometer, Thermo Scientific, USA). All experiments were done in duplicate.

The drug uptake (i.e. adsorbent loading) was calculated from the following equation (Eq. 1):

$q_{e}=\frac{\left(C_{0}-C_{e}\right) \cdot V}{m}$

where $q_{e}(\mathrm{mg} / \mathrm{g})$ is the mass of adsorbed DS per unit mass of the adsorbent (starting diatomite or modified diatomite) at equilibrium, $C_{o}$ is the initial concentration of DS solution $(\mathrm{mg} / \mathrm{ml}), C_{e}$ is the concentration of DS in the solution at equilibrium $(\mathrm{mg} / \mathrm{ml}), V$ is the volume of the reacting dispersion, $m$ is the mass of the adsorbent.

Dependence of the adsorbent loading on the adsorbate concentration in the state of equilibrium at the constant temperature is mathematically described by an isotherm equation. Two most frequently used isotherm equations for the fitting of experimental equilibrium data are the Langmuir and the Freundlich isotherms.

The Langmuir isotherm in its linear form is given by the following equation (Eq. 2):

$$
\frac{C_{e}}{q_{e}}=\frac{1}{q_{\max } K_{L}}+\frac{1}{q_{\max }} C_{e}
$$

where $C_{e}$ is the concentration of DS in the solution at equilibrium $(\mathrm{mg} / \mathrm{ml}), q_{e}$ is the mass of adsorbed DS per unit mass of the adsorbent at equilibrium $(\mathrm{mg} / \mathrm{g}), K_{L}$ is the Langmuir isotherm constant $(\mathrm{ml} / \mathrm{mg})$ and $q_{\max }$ is the maximum monolayer coverage capacity $(\mathrm{mg} / \mathrm{g})$. The theoretically derived Langmuir isotherm model assumes monolayer coverage of the adsorbent surface and energetic homogeneity of the adsorption sites.

The Freundlich isotherm in its linear form is given by the following equation (Eq. 3): 
$\log q_{e}=\log K_{F}+\frac{1}{n} \log C_{e}$

where $C_{e}$ is the concentration of DS in the solution at equilibrium $(\mathrm{mg} / \mathrm{ml}), q_{e}$ is the mass of adsorbed DS per unit mass of the adsorbent at equilibrium $(\mathrm{mg} / \mathrm{g}), K_{F}$ is the Freundlich isotherm constant $(\mathrm{mg} / \mathrm{g})(\mathrm{mg} / \mathrm{ml})^{\mathrm{n}}$ related to the adsorption capacity and $1 / n$ is a constant related to the adsorption intensity and energetic heterogeneity of the adsorbent surface. The empirically derived Freundlich isotherm model can be applied to adsorption onto heterogeneous surfaces.

Adsorption isotherm data were fitted to the abovementioned isotherm equations by linear regression analysis. The isotherm equation applicability was based on a comparison of the determination coefficient $\left(r^{2}\right)$.

\subsubsection{In vitro drug release studies}

The flat-face punches with a diameter of $13 \mathrm{~mm}$ were used to compress powder samples containing DS adsorbed onto the starting (DD) or modified diatomite (MDD) and physical mixture of DS with modified diatomite (PMDD) into $300 \mathrm{mg}$ comprimates using an eccentric tablet machine (EKO Korsch, Germany). The drug adsorption was carried under conditions corresponding to the final point on isotherm curves.

Drug release from the comprimates was studied using a closed loop configuration of the flowthrough cell CE 7smart Dissolution Apparatus (SOTAX AG, Switzerland) in $900 \mathrm{ml}$ of phosphate buffer $\mathrm{pH} 7.5$ under a constant medium flow rate of $8 \mathrm{ml} / \mathrm{min}$ at $37{ }^{\circ} \mathrm{C}$. The comprimates were put into wire sinkers and tested for drug release as such. At the predetermined time intervals $4 \mathrm{ml}$ of medium were withdrawn, replaced with the equal volume of fresh medium, filtered and the amount of DS released in filtrate was assayed spectrophotometrically. All experiments were done in triplicate. Results were expressed as a percent of released drug versus time.

The HPLC analysis of DS content in powder samples containing DS adsorbed onto the starting (DD) or modified diatomite (MDD) was performed on a Dionex Ultimate 3000 system (Thermo 
Fisher Scientific, Germering, Germany) equipped with Dionex Ultimate 3000 quaternary pump, autosampler and UV detector. For data acquisition Chromeleon 7 software (Thermo Fisher Scientific, Germering, Germany) was used. The column chosen was a Zorbax Extend-C18 (150 mm $\times 4.6 \mathrm{~mm}, 5 \mu \mathrm{m}$ particle size). The mobile phase consisted of methanol and water $(80: 20, \mathrm{v} / \mathrm{v})$ and $\mathrm{pH}$ of the mobile phase was adjusted to 2.5 with ortho-phosphoric acid. The column temperature was adjusted to $30^{\circ} \mathrm{C}$ and the flow rate was $1 \mathrm{ml} / \mathrm{min}$. The UV detection was performed at $254 \mathrm{~nm}$.

To evaluate the mechanism of DS release from the comprimates, the release data were fitted to various mathematical models (Table 1) (Costa and Lobo, 2001).

[Table 1]

Drug release profiles were fitted to the mathematical models by linear regression analysis. The model applicability was based on a comparison of the determination coefficient $\left(r^{2}\right)$.

\subsubsection{Acute toxicity test}

NMRI HAN mice $(n=5)$ from Biomedical Research Center, R\&D Institute (Galenika, a.d., Belgrade, Serbia), weighing 19-21 g were used for acute toxicity test. All experiments were performed according to a protocol approved by the Institutional Animal Care and Use Committee and were carried out in compliance with the NIH Guide for Care and Use of Laboratory Animals (NRC Committee for the Update of the Guide for the Care and Use of Laboratory Animals, 2011). The animals, left for at least 3 days for acclimatization to animal room condition, were housed in groups of five per cage $\left(42.5 \times 27 \times 19 \mathrm{~cm}^{3}\right)$ and maintained on a $12 / 12 \mathrm{~h} \mathrm{light/dark}$ cycle at $22 \pm 1{ }^{\circ} \mathrm{C}$ and $60 \%$ relative humidity. Food and water were freely available, except during the experimental procedure. 
The dose of $2000 \mathrm{mg} / \mathrm{kg}$ for the starting and the modified diatomite was administered via oral route according to FDA guidance for Potential excipient intended for short term use (CDER, 2005) and internal regulations (Research \& Development, Galenika a.d., Belgrade) for acute toxicity testing. During observation period $(72 \mathrm{~h})$ treated animals were observed for death and any symptoms of toxicity.

\section{Results and discussion}

\subsection{Characterization of the starting and modified diatomite before and after drug adsorption}

The starting diatomite sample complied with the limit test A for heavy metals and pharmacopoeial requirements for microbiological quality.

Laser diffraction analysis of the starting sample's three batches performed on a Mastersizer 2000 (Malvern Instruments Ltd., UK) confirmed batch to batch consistency with mean volume diameter $48.4 \pm 11.3 \mu \mathrm{m}$ and the absence of particles smaller than $1 \mu \mathrm{m}$.

Refined diatomite from Kolubara basin mostly comprised centric frustules of discoid shape with pore rows radiating from the central point on circular valves. Centric frustules of cylindrical shape with straight pore rows on the mantle were less represented (Fig. 1 a). Original diatomite structure was retained even after modification (Fig. 1 b) and adsorption of DS on the starting or modified diatomite (Fig. $1 \mathrm{c}$ and d). Element distribution maps show homogeneous distribution of chlorine (element originating from DS) in the sample obtained after DS adsorption on the starting diatomite, whereas inhomogeneous chlorine distribution was observed in the sample obtained after DS adsorption on the modified diatomite (images not shown).

[Fig. 1] 
The results of EDS analysis are presented in Table 2. As expected, silicon and oxygen are prevalent elements in the starting diatomite. After diatomite modification an increase in aluminum and sulfur content and a decrease in silicon content were observed due to the presence of partially neutralized aluminum sulfate. An increase in chlorine content was noticed after DS adsorption onto the starting and modified diatomite, confirming the presence of the drug in DD and MDD samples. Higher chlorine content in MDD sample compared to DD sample corresponds with significantly higher adsorbent loading of MD with DS. Interestingly, sodium was not detected in DD and MDD samples, potentially indicating that the adsorbed drug was not in its sodium salt form.

[Table 2]

X-ray diffractograms of D, MD, DS, DD and MDD samples are presented in Fig. 2. The XRD pattern of $\mathrm{D}$ is typical of diatomaceous silica i.e. a broad reflection at $2 \theta=20-25^{\circ}$ confirms opal-A structure of amorphous hydrated silica (Šljivić et al., 2009). Diffraction peaks at $2 \theta=20.8^{\circ}, 26.6^{\circ}$ and $36.5^{\circ}$ correspond to quartz and those at $2 \theta=8.8^{\circ}, 17.7^{\circ}, 19.7^{\circ}, 25.4^{\circ}, 26.6^{\circ}$ and $34.8^{\circ}$ correspond to illite. These results are in accordance with literature data on mineralogical composition of diatomite from Kolubara (Obradović et al., 1994) and the expected forms of concomitant minerals after calcination at $550{ }^{\circ} \mathrm{C}$. Precisely speaking, illite may have undergone both dehydration and dehydroxylation (Földvári, 2011; Jiang et al., 2008) during the refinement of Kolubara diatomite, but dehydroxylation does not lead to noticeable variations in the X-ray diffraction pattern of illite until structural breakdown at about $900{ }^{\circ} \mathrm{C}$ (Murad and Wagner, 1996). Partially neutralized aluminum sulfate (BAS), which was prepared separately for characterization purposes, appeared to be amorphous. The diffraction pattern of MD, with a broad reflection corresponding to amorphous hydrated silica and peaks relating to quartz and illite, complies with that of diatomite confirming no structural change has occurred during modification process. Diffraction peaks originating from DS were not observed in DD diffractogram due to either low 
content of the adsorbed drug or as a result of the adsorbed drug's presence in an amorphous form. Interestingly, new diffraction peaks, mostly not corresponding to those of the pure drug, appeared in MDD diffractogram pointing to the formation of a new crystalline phase during DS adsorption onto modified diatomite. Compared to literature data on X-ray diffraction patterns of various diclofenac forms (Lai et al., 2009; Castellari and Ottani, 1997) it can be concluded that the drug is adsorbed onto MD in its acidic form.

[Fig. 2]

The FTIR spectra of D, MD, DS, DD and MDD samples are shown in Fig. 3. In the FTIR spectrum of D the bands at $455 \mathrm{~cm}^{-1}, 799 \mathrm{~cm}^{-1}$ and $1064 \mathrm{~cm}^{-1}$, connected to Si-O-Si bending, symmetric and asymmetric stretching respectively, originate from diatomaceous silica (Gulturk and Guden, 2011; Ilia et al., 2009). Quartz and illite (dehydroxylated), impurities present in thermally treated diatomite as indicated by XRPD analysis, also give some characteristic bands (Jiang et al., 2008; Vaculíková and Plevová, 2005; Oumabady Alias Cannane et al., 2013) in the same region as diatomaceous silica. A broad band between $3200 \mathrm{~cm}^{-1}$ and $3550 \mathrm{~cm}^{-1}$ can be assigned to $\mathrm{O}-\mathrm{H}$ stretching and a weak bend at $1631 \mathrm{~cm}^{-1}$ to $\mathrm{H}-\mathrm{O}-\mathrm{H}$ bending. Characteristic bands of diatomaceous silica were also present in the FTIR spectrum of MD (appearing at $456 \mathrm{~cm}^{-1}, 796 \mathrm{~cm}^{-1}$ and $1065 \mathrm{~cm}^{-}$ ${ }^{1}$ ), indicating no change in diatomite structure occurred during modification. When comparing FTIR spectrum of MD to the one of D, small increase in the intensity of a band at $1634 \mathrm{~cm}^{-1}(\mathrm{H}-\mathrm{O}-$ $\mathrm{H}$ bending) and more pronounced increase in the intensity of a broad bend centered at $3373 \mathrm{~cm}^{-1}$ $(\mathrm{O}-\mathrm{H}$ stretching) were noticed due to the presence of partially neutralized aluminum sulfate in hydrous form.

The bands at $457 \mathrm{~cm}^{-1}, 799 \mathrm{~cm}^{-1}$ and $1064 \mathrm{~cm}^{-1}$ in the FTIR spectrum of DD, and those at $459 \mathrm{~cm}^{-1}$, $800 \mathrm{~cm}^{-1}$ and $1069 \mathrm{~cm}^{-1}$ in the FTIR spectrum of MDD derive from diatomaceous silica implying that adsorption onto the starting and modified diatomite hasn't altered diatomite structure. The 
presence of the adsorbed drug is confirmed by the weak bands at $1453 \mathrm{~cm}^{-1}, 1506 \mathrm{~cm}^{-1}$ and 1628 $\mathrm{cm}^{-1}$ in the FTIR spectrum of DD. Peak pairs at $1451 \mathrm{~cm}^{-1}, 1468 \mathrm{~cm}^{-1}$ and $1497 \mathrm{~cm}^{-1}, 1507 \mathrm{~cm}^{-1}$ in the FTIR spectrum of DS, assigned to drug's aromatic ring stretch, are also present in the FTIR spectra of DD (appearing at $1453 \mathrm{~cm}^{-1}$ and $1506 \mathrm{~cm}^{-1}$ ) and MDD (appearing at $1452 \mathrm{~cm}^{-1}$ and 1507 $\mathrm{cm}^{-1}$ ). A band at $3257 \mathrm{~cm}^{-1}$ in the FTIR spectrum of DS, which is connected to $\mathrm{N}-\mathrm{H} \cdots \cdot \mathrm{O}$ vibrations of intramolecular hydrogen bonding (Ghizdavu and Ghizdavu, 2007), disappeared in the FTIR spectrum of MDD, indicating spatial rearrangement related to secondary amino group during adsorption of DS onto MD. The N-H stretching band at $3387 \mathrm{~cm}^{-1}$ in the FTIR spectrum of DS (Ghizdavu and Ghizdavu, 2007) shifted to a lower wavenumber $\left(3321 \mathrm{~cm}^{-1}\right)$ in the FTIR spectrum of MDD. The DS bands at $3387 \mathrm{~cm}^{-1}$ and $3257 \mathrm{~cm}^{-1}$ are obscured by a broad band between 3200 $\mathrm{cm}^{-1}$ and $3550 \mathrm{~cm}^{-1}$ in the FTIR spectrum of DD. Therefore, the involvement of secondary amino group in DS adsorption onto the starting diatomite is inconclusive.

The bands at $1573 \mathrm{~cm}^{-1}$ and $1397 \mathrm{~cm}^{-1}$ in the IR spectra of DS were ascribed to asymmetric and symmetric stretching of carboxylate respectively, according to literature data on DS (Ghizdavu and Ghizdavu, 2007; Kovala-Demertzi et al., 1998). In the FTIR spectrum of DD the band linked to symmetric stretching of carboxylate $\left(1397 \mathrm{~cm}^{-1}\right)$ disappeared and the band linked to asymmetric stretching of carboxylate $\left(1573 \mathrm{~cm}^{-1}\right)$ shifted to higher wavenumber $\left(1628 \mathrm{~cm}^{-1}\right)$ and broadened. Similar changes, related to carboxylate stretching bands, occurred in the FTIR spectrum of MDD. Bands ascribed to carboxylate symmetric and asymmetric stretching shifted to higher wavenumbers (appearing in the spectrum of MDD at $1412 \mathrm{~cm}^{-1}$ and $1690 \mathrm{~cm}^{-1}$, respectively).

Peak shifts related to carboxylate group indicated its involvement in DS adsorption on the starting and modified diatomite. A literature review on the FTIR spectra of diclofenac forms (Palomo et al., 1999; Baena Aristizábal et al., 2011) revealed the compliance of shifted/new peaks in the spectra of MDD to those of diclofenac acid. The peaks at $3321 \mathrm{~cm}^{-1}, 1690 \mathrm{~cm}^{-1}$ and $938 \mathrm{~cm}^{-1}$, observed in the FTIR spectrum of MDD, correspond to N-H stretching of secondary amino group, $\mathrm{C}=\mathrm{O}$ stretching of carboxylic acid group and $\mathrm{O}-\mathrm{H}$ bending of carboxylic acid group. 
[Fig. 3]

The results of thermal analyses are graphically presented in Supplementary Materials. The starting diatomite sample exhibited prominent mass loss up to $164{ }^{\circ} \mathrm{C}$, followed by a small continuous mass loss upon further heating. Approximately $2.1 \%$ mass was lost after heating of the starting diatomite to around $1000{ }^{\circ} \mathrm{C}$. Strong broad endothermic peak centered at $114{ }^{\circ} \mathrm{C}$ indicating dehydration of the sample (Ilia et al., 2009) and an exothermic peak at $955{ }^{\circ} \mathrm{C}$ related to the destruction of the lattice and formation of a spinel from illite (Földvári, 2011) were observed in the DTA curve of the starting diatomite. Modified diatomite exhibited distinctive mass loss in two temperature regions with total $8.1 \%$ mass loss at the end of the heating treatment. In the DTA curve of MD broad endothermic peak centered at $147{ }^{\circ} \mathrm{C}$ resulted from dehydration, small endothermic peaks at 550 ${ }^{\circ} \mathrm{C}, 616{ }^{\circ} \mathrm{C}$ and $668{ }^{\circ} \mathrm{C}$ were ascribed to dehydroxylation and strong endothermic peak at $825{ }^{\circ} \mathrm{C}$ to desulfurization of partially neutralized aluminum sulfate according to analogy with thermal behavior of aluminite and sodium/potassium alunite (Földvári, 2011; Kashkai and Babaev, 1969). Marked mass change of DD occurred until $606{ }^{\circ} \mathrm{C}$ and a less pronounced mass change continued after $726^{\circ} \mathrm{C}$. Total mass loss of DD at the end of the heating treatment was $4.4 \%$. Major features in the DTA curve of DD were: broad endothermic peak centered at $143{ }^{\circ} \mathrm{C}$ representing sample dehydration and strong exothermic peak at $493{ }^{\circ} \mathrm{C}$ related to the adsorbed drug's oxidative decomposition. The weight loss of MDD upon heating was carried out in four stages and approximately $13.7 \%$ mass was lost after heating to $1000{ }^{\circ} \mathrm{C}$. In the DTA curve of MDD broad endothermic peak centered at $113{ }^{\circ} \mathrm{C}$ and another at $194{ }^{\circ} \mathrm{C}$ were ascribed to dehydration, strong exothermic peak at $485{ }^{\circ} \mathrm{C}$ was linked to oxidative decomposition of the drug and an endothermic peak at $853{ }^{\circ} \mathrm{C}$ was related to desulfurization of MD residue.

According to literature (Llinàs et al., 2007), when DS is heated under a nitrogen purge, it melts within a range $283-285{ }^{\circ} \mathrm{C}$ followed by immediate decomposition. However, heating of DS under 
dynamic flow of synthetic air causes (partial) oxidation/decomposition prior to the melting (Tudja et al., 2001). Diclofenac acid also displays differences in thermal behavior related to the environmental conditions. When heated under a nitrogen purge, diclofenac acid melts at $180.5^{\circ} \mathrm{C}$ (Llinàs et al., 2007), but when heating is carried under dynamic flow of air, degradation (intramolecular cyclization and condensation) occurs before melting at $158{ }^{\circ} \mathrm{C}$ (Giordano et al., 2003). However, from major exothermic events in DTA curves of DD (493 $\left.{ }^{\circ} \mathrm{C}\right)$ and MDD (485 ${ }^{\circ} \mathrm{C}$ ), which were ascribed to oxidative decomposition of the adsorbed drug, it can be concluded that thermal behavior of diclofenac on a carrier (starting or modified diatomite) is quite different than that of the pure DS or diclofenac acid. Furthermore, temperature of the main exothermic peak (507 ${ }^{\circ} \mathrm{C}$ ) in the DTA curve of PMDD (physical mixture of DS with MD) is close to the temperature of the major exothermic peaks in DTA curves of DD and MDD. It may be presumed that interaction of the drug (adsorbed or free) with the carrier influences thermal degradation of diclofenac under oxidative atmosphere.

\subsection{Adsorption isotherm studies}

Compared to food grade diatomite, whose adsorbent loading with DS was $20.2 \mathrm{mg} / \mathrm{g}$ (Janićijević et al., 2014), refined diatomite from Kolubara basin had approximately 2.1 times higher adsorbent loading with DS (42.4 mg/g) (Fig. 4). Even so, it was still not feasible to use DS adsorption onto refined diatomite from Kolubara as a drug loading procedure which would enable the preparation of acceptable size comprimates containing therapeutic dose of the drug. Modification of refined Kolubara's diatomite with partially neutralized aluminum sulfate increased adsorbent loading by 8.8 times (373.2 mg/g) (Fig. 4). Comparable modification of food grade diatomite also lead to pronounced increase in adsorbent loading $(250.3 \mathrm{mg} / \mathrm{g}$ ) compared to the starting material (Janićijević et al., 2014). Although adsorbent loading with DS was up to 1.5 times higher for modified Kolubara's diatomite compared to modified food grade diatomite it has to be pointed that 
different adsorption conditions (i.e. different adsorbent mass to adsorbate solution volume ratio) were applied in our previous work. However, generally speaking, inorganic modification of diatomite significantly increases adsorbent loading with DS, allowing the usage of adsorption as a drug loading procedure which enables the preparation of comprimates having therapeutic dose of the drug.

[Fig. 4]

Adsorption of DS onto modified diatomite was best described by the Langmuir isotherm model (Fig. 4) implying monolayer coverage of DS onto modified diatomite surface. Calculated maximum adsorbent loading of modified diatomite with DS was $390.02 \mathrm{mg} / \mathrm{g}$. During investigations of DS adsorption onto modified or unmodified aluminosilicates (zeolites and clays) much lower values of maximum adsorbent loading were obtained for cetylpyridinium chloride-modified zeolite (159.57 mmol/kg) (Krajišnik et al., 2011), hexadecyltrimethylammonium bromide-modified zeolite (45.87 $\mathrm{mg} / \mathrm{g}$ ) and benzalkonium chloride-modified zeolite $(31.35 \mathrm{mg} / \mathrm{g}$ ) (Krajišnik et al., 2010), while higher value of maximum adsorbent loading was demonstrated for montmorillonite $(680.27 \mathrm{mg} / \mathrm{g})$ (Kaur and Datta, 2014).

It has to be noted that the Freundlich isotherm model also has high determination coefficient $\left(\mathrm{r}^{2}=\right.$ 0.926), but it does not describe the drug adsorption on MD as closely as the Langmuir model. However, calculated value of the Freundlich model parameter $1 / \mathrm{n}$, which is in the interval from 0 to 1, suggests the adsorption of DS onto modified diatomite is favorable.

\subsection{In vitro drug release studies and drug release kinetics}

DS was loaded onto D and MD by employing the same procedure as in adsorption isotherm studies under conditions providing the highest adsorbent loading (DS solution concentration $4 \mathrm{mg} / \mathrm{ml}$, 
equilibrium time period of $2 \mathrm{~h}$ and $6 \mathrm{~h}$ for $\mathrm{D}$ and MD respectively). Due to low adsorbent loading of $\mathrm{D}$, the drug content in DD comprimates ( $14 \mathrm{mg}$ per comprimate) was significantly lower than the drug's therapeutic dose. Conversely, high adsorbent loading of MD enabled the preparation of MDD comprimates containing therapeutic daily dose of DS ( 80 mg per comprimate), which is very important feature for potential therapeutic application of this drug carrier in various pharmaceutical dosage forms. Drug release experiments were also performed from comprimates containing physical mixture of DS with MD (PMDD), whose drug content was the same as in the MDD comprimates. The physical mixture was prepared by geometric dilution using a pestle and a mortar and blended long enough to ensure adequate homogenization.

The DS release profiles from DD, MDD and PMDD comprimates are shown in Fig. 5.

[Fig. 5]

DD comprimates, which delaminated and disintegrated during the study, showed rapid drug release in the first hour ( $82 \%$ of DS released in $60 \mathrm{~min}$ ), followed by slow drug release until the third hour of the study ( $93 \%$ of DS released in 180 min). Conversely, both MDD and PMDD comprimates released the drug permanently in a sustained manner over a period of $8 \mathrm{~h}$. During that time no significant change in the appearance of these comprimates was noticed. In $8 \mathrm{~h}$ PMDD comprimates released $45 \%$ of the drug which was somewhat higher than MDD comprimates which released 37\% of the drug.

Two major conclusions can be drawn when the results of DS release from MDD and PMDD comprimates in phosphate buffer $\mathrm{pH} 7.5$ are compared to our previously presented results of DS release from the corresponding DAMD and PMDMD comprimates in phosphate buffer $\mathrm{pH} 6.8$ (Janićijević et al., 2014). Firstly, comprimates containing either DS adsorbed onto the modified diatomite or the physical mixture of DS with the modified diatomite show permanent and sustained DS release over $8 \mathrm{~h}$ time regardless of diatomite origin and differences in the $\mathrm{pH}$ value of the testing 
medium. Secondly, physical mixtures of DS with the modified diatomite give similar percentage of cumulative drug release in $8 \mathrm{~h}$, while comprimates containing DS adsorbed onto the modified diatomite show significant differences in cumulative drug release percentage at the end of the testing period. Approximately 2 times higher drug release in $8 \mathrm{~h}$ was achieved for comprimates containing DS adsorbed onto modified Kolubara's diatomite compared to those containing DS adsorbed onto modified food grade diatomite. This observation may be explained by different physicochemical properties of the modified diatomite samples used as carriers or by differences in the $\mathrm{pH}$ values of the testing media.

During DS release from MDD desorption of the drug occurs, while drug release from PMDD results from equilibrium between dissolution of DS particles and adsorption of dissolved DS onto MD. These processes may be affected by phosphate anions.

Phosphate anions are known to have strong affinity for alumina (Hsu, 1989) and they can be adsorbed on aluminum (hydr)oxides by combination of surface complexation and surface precipitation, with relative contribution of these processes in adsorption mechanism depending on pH and phosphate concentration/loading (Van Emmerick et al., 2007; Del Nero et al., 2010). Furthermore, phosphate anions reduce the adsorption of certain mono- and dicarboxylic acids on aluminum (oxide) hydroxide (Guan et al., 2006; Schefe et al., 2009), but they promote desorption of natural organic matter (humic and fulvic acids-complex and heterogeneous mixtures of compounds containing carboxylic acid groups and phenolic groups) from amorphous aluminum hydroxide (Kaiser and Zech, 1999). Based on these findings, higher DS release can be expected from both PMDD and MDD comprimates at $\mathrm{pH} 6.8$ than at $\mathrm{pH} 7.5$ due to higher concentration of $\mathrm{H}_{2} \mathrm{PO}_{4}^{-}$ions at $\mathrm{pH}$ 6.8. However, different results obtained in our studies imply that the influence of phosphate anions on adsorption/desorption of the drug is not a major factor affecting DS release from the comprimates. It can be speculated that factors such as the porosity and wettability rate of the comprimates with different carriers play more important role in DS release. 
Drug release profiles from comprimates were fitted to various drug release models and calculated model parameters are presented in Table 3.

[Table 3]

Drug release profiles from all three types of comprimates were best described by KorsmeyerPeppas model. The value of Peppas release exponent $n$ indicated that non-Fickian diffusion was the mechanism of DS release from MDD and PMDD, while Fickian diffusion governed DS release from DD comprimates.

\subsection{In vivo acute toxicity testing}

Potential new excipients proposed for use in drug products have to be appropriately evaluated for safety. The results of in vivo experiments demonstrated that the inorganically modified diatomite, as well as the starting diatomite, did not cause death or any kind of toxicological reaction during the period of observation. These findings corroborate the results of in vitro cytotoxicity studies on colon cancer cells showing diatomite was non-cytotoxic (Zhang et al., 2013) and favour potential pharmaceutical application of the abovementioned materials.

\section{Conclusion}

Local diatomite from Kolubara coal basin, after being refined by thermal treatment and sieving, complied with the pharmacopoeial (Ph. Eur. 6.0) requirements for heavy metals content and microbiological quality. In order to increase adsorbent loading of the starting diatomite with DS (42.4 mg/g) modification of diatomite was performed by precipitation of partially neutralized aluminum sulfate. Modified diatomite proved to have significantly higher adsorbent loading with 
diclofenac sodium $(373.2 \mathrm{mg} / \mathrm{g})$ which enabled the preparation of comprimates containing the adsorbed drug in therapeutic dose ( $~ 80 \mathrm{mg}$ per $300 \mathrm{mg}$ comprimate).

DS was adsorbed onto the starting diatomite most likely in an amorphous form as pointed by XRPD analysis and this process involved drug's carboxylate group according to FTIR spectrum analysis. Adsorption of DS onto modified diatomite resulted in the formation of a new crystalline phase with different spectral characteristics compared to pure DS. Further analyses and literature review revealed the compliance of diffraction pattern and FTIR spectrum peaks of this new phase to those of the diclofenac acid. Therefore, it was estimated that DS was adsorbed onto modified diatomite in its acidic form.

In vitro drug release studies in phosphate buffer $\mathrm{pH} 7.5$ demonstrated prolonged release of diclofenac sodium over $8 \mathrm{~h}$ not only from comprimates containing drug adsorbed onto the modified diatomite (37\% after $8 \mathrm{~h}$ ), but also from comprimates containing physical mixture of the drug with the modified diatomite ( $45 \%$ after $8 \mathrm{~h}$ ). In vivo acute toxicity testing of modified diatomite, as well as the starting diatomite, indicated on potential safety of these materials proposed for pharmaceutical excipients.

\section{Acknowledgments}

This work was realized within the framework of the project TR 34031 supported by The Ministry of Education, Science and Technological Development of the Republic of Serbia.

\section{References}

Baena Aristizábal, Y., Manzo, R.H., Ponce d'Leon Quiroga, L.F., 2011. Preparation and physicochemical characterization of some polyelectrolyte-diclofenac complexes. Vitae 18, 305-311. 
Bariana, M., Aw, M.S., Kurkuri, M., Losic, D., 2013. Tuning drug loading and release properties of diatom silica microparticles by surface modifications. Int. J. Pharm. 443, 230-241.

Castellari, C., Ottani, S., 1997. Two Monoclinic Forms of Diclofenac Acid. Acta Cryst. C53, 794797.

Center for Drug Evaluation and Research (CDER), 2005. Guidance for industry: Nonclinical studies for development of pharmaceutical excipients. FDA CDER, Rockville.

Costa, P., Lobo, J.M.S., 2001. Modeling and comparison of dissolution profiles. Eur. J. Pharm. Sci. $13,123-133$.

Del Nero, M., Galindo, C., Barillon, R., Halter, E., Madé, B., 2010. Surface reactivity of $\alpha$-Al2O3 and mechanisms of phosphate sorption: In situ ATR-FTIR spectroscopy and $\zeta$ potential studies. J. Colloid Interf. Sci. 342, 437-444.

Földvári, M., 2011. Handbook of thermogravimetric system of minerals and its use in geological practice. Geological Institute of Hungary, Budapest.

Ghizdavu, L.M., Ghizdavu, L., 2007. New metal coordination compounds of sodium \{2-[(2,6dichlorophenyl)amino]phenyl \}acetate. Stud. Univ. Babes-Bol. 52, 73-80.

Giordano, F., Rossi A., Pasquali, I., Bettini, R., Frigo, E., Gazzaniga, A., Sangalli, M.E., Mileo, V., Cattinela, S., 2003. Thermal degradation and melting point determination of diclofenac. J. Therm. Anal. Calorim. 73, 509-518.

Guan, X.H., Shang, C., Chen, G.H., 2006. Competitive adsorption of organic matter with phosphate on aluminum hydroxide. J. Colloid Interf. Sci. 296, 51-58.

Gulturk, E., Guden, M., 2011. Thermal and acid treatment of diatom frustules. J. Achiev. Mater. Manuf. Eng. 46, 196-203.

Hsu, P.H., 1989. Aluminum hydroxides and oxyhydroxides, in: Dixon, J.B., Weed, S.B. (Eds), Minerals in Soil Environments. Soil Science Society of America, Madison, Wisconsin, pp. 331378. 
Ilia, I.K., Stamatakis, M.G., Perraki, T.S., 2009. Mineralogy and technical properties of clayey diatomites from north and central Greece. Cent. Eur. J. Geosci. 1, 393-403.

Janićijević, J., Krajišnik, D., Čalija, B., Dobričić, V., Daković, A., Krstić, J., Marković, M., Milić, J., 2014. Inorganically modified diatomite as a potential prolonged-release drug carrier. Mater. Sci. Eng. C 42, 412-420.

Jiang, T., Li, G., Qiu, G., Fan, X., Huang, Z., 2008. Thermal activation and alkali dissolution of silicon from illite. Appl. Clay Sci. 40, 81-89.

Kaiser, K., Zech, W., 1999. Release of Natural Organic Matter Sorbed to Oxides and a Subsoil. Soil Sci. Soc. Am. J. 63, 1157-1166.

Kashkai, M.A., Babaev, I.A., 1969. Thermal investigations on alunite and its mixtures with quartz and dickite. Mineral. Mag. 37, 128-134.

Kaur, M., Datta, M., 2014. Diclofenac Sodium Adsorption onto Montmorillonite: Adsorption Equilibrium Studies and Drug Release Kinetics. Adsorpt. Sci. Technol. 32, 365-387.

Kovala-Demertzi, D., Hadjikakou, S., Demertzis, M., Deligiannakis, Y., 1998. Preparation and properties of manganese (II), cobalt (II) and nickel (II) complexes of diclofenac with potentially interesting anti-infammatory activity: Behavior in the oxidation of 3,5-di-tert-butyl-o-catechol. J. Inorg. Biochem. 69, 223-229.

Krajišnik, D., Daković, A., Milojević, M., Malenović, A., Kragović, M., Bajuk Bogdanović, D., Dondur, V., Milić, J., 2011. Properties of diclofenac sodium sorption onto natural zeolite modified with cetylpyridinium chloride. Colloid. Surface. B 83, 165-172.

Krajišnik, D., Milojević, M., Malenović, A., Daković, A., Ibrić, S., Savić, S., Dondur, V., Matijašević, S., Radulović, A., Daniels, R., Milić, J., 2010. Cationic surfactants-modified natural zeolites: improvement of the excipients functionality. Drug Dev. Ind. Pharm. 36, 1215-1224.

Lai, F., Sinico, C., Ennas, G., Marongiu, F., Marongiu, G., Fadda, A.M., 2009. Diclofenac nanosuspensions: Influence of preparation procedure and crystal form on drug dissolution behaviour. Int. J. Pharm. 373, 124-132. 
Llinàs, A., Burley, J.C., Box, K.J., Glen, R.C., Goodman, J.M., 2007. Diclofenac Solubility: Independent Determination of the Intrinsic Solubility of Three Crystal Forms. J. Med. Chem. 50, 979-983.

Losic, D., Mitchell, J.G., Voelcker, N.H., 2009. Diatomaceous Lessons in Nanotechnology and Advanced Materials. Adv. Mater. 21, 1-12.

Meyers, M.A., Chen, P.Y., Lin, A.Y.M., Seki, Y., 2008. Biological materials: Structure and mechanical properties. Prog. Mater. Sci. 53, 1-206.

Murad, E., Wagner, U., 1996. The thermal behavior of an Fe-rich illite. Clay Minerals 31, 45-52.

National Research Council (US) Committee for the Update of the Guide for the Care and Use of Laboratory Animals, 2011. Guide for the care and use of laboratory animals, 8th ed. The national academies press (US), Washington DC.

Obradović, J., Hein, J.R., Djurdjević, J., 1994. Diagenesis of diatomite from the Kolubara Coal Basin, Baroševac, Serbia. Geol. J. 29, 209-217.

Oumabady Alias Cannane, N., Rajendran, M., Selvaraju, R., 2013. FT-IR spectral studies on polluted soils from industrial area at Karaikal, Puducherry State, South India. Spectrochim. Acta A $110,46-54$.

Palomo, M.E., Ballesteros, M.P., Frutos, P., 1999. Analysis of diclofenac sodium and derivatives. J. Pharmaceut. Biomed. 21, 83-94.

Schefe, C.R., Kappen, P., Zuin, L., Pigram, P.J., Christensen, C., 2009. Addition of carboxylic acids modifies phosphate sorption on soil and boehmite surfaces: A solution chemistry and XANES spectroscopy study. J. Colloid Interf. Sci. 330, 51-59.

Su, B.L., Sanchez, C., Yang, X.Y. (Eds), 2012. Hierarchically Structured Porous Materials: From Nanoscience to Catalysis, Separation, Optics, Energy, and Life Science. Wiley-VCH Verlag GmbH \& Co. KGaA, Weinheim.

Šljivić, M., Smičiklas, I., Pejanović, S., Plećaš, I., 2009. Comparative study of $\mathrm{Cu}^{2+}$ adsorption on a zeolite, a clay and a diatomite from Serbia. Appl. Clay Sci. 43, 33-40. 
Tudja, P., Khan, M.Z.I., Meštrović, E., Horvat, M., Golja, P., 2001. Thermal Behaviour of

Diclofenac Sodium: Decomposition and Melting Characteristics. Chem. Pharm. Bull. 49 (10), $1245-1250$.

U.S. Geological Survey, 2014. Mineral Commodity Summaries 2014. U.S. Geological Survey, Reston, Virginia, pp. 52-53.

Vaculíková, L., Plevová, E., 2005. Identification of clay minerals and micas in sedimentary rocks. Acta Geodyn. Geomater. 2, 167-175.

Van Emmerick, T.J., Sandström, D.E., Antzutkin, O.N., Angove, M.J., Johnson, B.B., 2007. P-31 solid-state nuclear magnetic resonance study of the sorption of phosphate onto gibbsite and kaolinite. Langmuir 23, 3205-3213.

Zhang, H., Shahbazi, M.A., Mäkilä, E.M., da Silva, T.H., Reis, R.L., Salonen, J.J., Hirvonen, J.T., Santos, H.A., 2013. Diatom silica microparticles for sustained release and permeation enhancement following oral delivery of prednisone and mesalamine. Biomaterials 34, 9210-9219.

\section{Figure captions}

Fig. 1. SEM micrographs of the starting diatomite (a), modified diatomite (b), starting diatomite with adsorbed DS (c), modified diatomite with adsorbed DS (d)

Fig. 2. X-ray diffractograms of D, MD, DS, DD and MDD samples

Reflections related to quartz and illite were labeled with Q and I and those corresponding to acidic form of diclofenac were labeled with asterisk

Fig. 3. FTIR spectra of D, MD, DS, DD and MDD samples 
Fig. 4. Adsorption isotherms for D and MD samples and the parameters of adsorption isotherm models $(n=2)$

Fig. 5. Drug release profiles from DD, MDD and PMDD comprimates $(\mathrm{n}=3)$ 